\title{
ORIENTALISMO E A QUESTÃO DOS MOVIMENTOS DAS MULHERES DO IRAQUE DESAFIOS E REFLEXÕES ${ }^{1}$
}

\author{
ORIENTALISM AND THE ISSUE OF IRAQ'S \\ WOMEN'S MOVEMENT \\ CHALLENGES AND REFLECTIONS
}

\author{
Luiza Delaflora Cassol ${ }^{2}$ \\ Maria Eduarda Oliveira Dall'Áqua ${ }^{3}$ \\ Sabrina da Costa Chiuza ${ }^{4}$
}

\begin{abstract}
RESUMO: Este artigo analisa as limitações e desafios que o discurso orientalista promovido pelo Ocidente apresenta à interpretação das mulheres do Iraque e seus movimentos, e como ele ofusca sua participação histórica na política do país. Através de uma análise de discurso de notícias de 5 emissoras dos Estados Unidos no período pós-invasão do Iraque (20032013), percebe-se que ocorre reafirmação do discurso orientalista de estereótipos sobre a mulher árabe e da sua necessidade de interferência externa.

Palavras-Chave: Orientalismo; Feminismo Transnacional; Movimento das Mulheres; Iraque; Análise de Discurso Jornalístico.
\end{abstract}

ABSTRACT: This paper analyses the limitations and challenges that Orientalist discourse promoted by the West presents to the interpretation of Iraqi women and their movements, and how it overshadows their historical political participation in the country. This is done through a news' discourse analysis of 5 broadcasters in the U.S. discoursing over postinvasion Iraq (2003-2013) and how it brings out an orientalist discourse that sets forth an arab woman stereotype and their need of external interference.

Keywords: Orientalism; Transnational Feminism; Women's Movement; Iraq; Journalistic Discourse Analysis.

\section{INTRODUÇÃO}

\footnotetext{
1 A ideia para este artigo surgiu durante a disciplina de Relações Internacionais do Oriente Médio, ministrada pelo Prof. Dr. Igor Castellano da Silva, no curso de Relações Internacionais da Universidade Federal de Santa Maria - UFSM. Dessa forma, gostaríamos de agradecer ao professor pela atenção e otimismo quanto ao trabalho, nos incentivando com comentários e sugestões.

2 Graduanda de Relações Internacionais pela Universidade Federal de Santa Maria - UFSM, integrante do Grupo de Estudos em Capacidade Estatal, Segurança e Defesa (GECAP). ORCID: https://orcid.org/0000-00028302-4627. Link para o Currículo Lattes: http://lattes.cnpq.br/4866713086354184. Contato: luizacassol98@ gmail.com.

${ }_{3}$ Graduada em Relações Internacionais pela Universidade Federal de Santa Maria - UFSM, integrante do Programa de Extensão Gênero, Interseccionalidade e Direitos Humanos (PRE/UFSM). ORCID ID: https:// orcid.org/0000-0001-6452-6675. Link para o Currículo Lattes: http://lattes.cnpq.br/8965333264977684. Contato: medallaqua@gmail.com.

${ }^{4}$ Graduanda de Relações Internacionais pela Universidade Federal de Santa Maria, bolsista do Programa de Extensão Gênero, Interseccionalidade e Direitos Humanos (PRE/UFSM). ORCID ID: https://orcid. org/0000-0001-9121-4685. Link para o Currículo Lattes: http://lattes.cnpq.br/7847223022830673. Contato: sabrinachiuza@hotmail.com.
} 
O Iraque é um país em que os movimentos sociais e políticos de mulheres sempre estiveram muito presentes historicamente. Antes um país à frente dos direitos das mulheres no Oriente Médio, após a Guerra do Golfo de 1991 e a invasão dos EUA em 2003, tornou-se um dos piores lugares da região para as mulheres (Thomas Reuters Foundation, 2013). 0 choque econômico negativo decorrente das guerras gerou um impacto nas vidas e nos direitos das mulheres iraquianas, gerando retrocessos e exacerbando problemas já existentes (Human Rights Watch, 2003; Stacy Banwell, 2015).

Com o objetivo de legitimar ainda mais uma intervenção para a retirada de Saddam Hussein do poder, os EUA no pós 11/09 construíram um discurso permeado pela preocupação com as violações e opressões dos direitos das mulheres cometidas pelo regime Ba'athista, o qual foi configurado por uma retórica de salvação da mulher iraquiana e catalisou uma interpretação unidimensional das mulheres dessa região (Saeid Neshat, 2003; Maryam Khalid, 2011; Christina Ho, 2010). Esse episódio, configura mais um exemplo, dentro de um histórico de construção de discursos orientalistas, que serviu como uma ferramenta a fim de auxiliar o Ocidente a adentrar e interferir no Oriente (o "outro").

Portanto, utilizando da teoria do Orientalismo proposta por Edward Said (1996) e da teoria feminista transnacional (Tina Campt, 2011; Simidele Dosekun, 2015; Rupal Oza, 2016; Mariana Chaise, 2016; Margaret McLaren, 2017), nos propormos a explorar, através de uma análise de discurso, como o orientalismo torna nebulosa a interpretação sobre os movimentos das mulheres do Iraque. A nossa hipótese sugere que o discurso orientalista influenciou na forma como as mulheres do Iraque e seus movimentos foram interpretados pela mídia estadunidense, sobretudo no período de 2003 a 2013.

Nosso estudo foi embasado em uma pesquisa bibliográfica, principalmente nos estudos de Nadje Al-Ali (2012) sobre a história dos movimentos das mulheres do Iraque, bem como em uma análise de discurso feita através de 20 notícias, do período de 2003 a 2013, das cinco principais emissoras estadunidenses, elencadas de acordo com uma pesquisa do Pew Research Center, sendo elas: ABC News, CBS News, CNN, FOX News e NBC News.

Através dessa análise, pudemos perceber como o discurso orientalista promovido pelo governo estadunidense e pela mídia ofuscou a mobilização das mulheres, de sua agência e desenvolvimento. A interpretação sobre essas mulheres baseava-se em sua cultura religiosa, nos abusos e violações sofridas, e na salvação e liberdade trazida pelos estadunidenses e seus aliados. De sua participação política, as dificuldades se sobressaíram, tornando-as como presas de circunstâncias intransponíveis. Para ilustrar esse contexto, o presente artigo se dividirá em quatro seções: (1) Abordagem conceitual - na qual serão abordados os conceitos do Discurso Orientalista e da Teoria Feminista Transnacional; (2) A Questão das Mulheres e o Orientalismo; (3) Os Movimentos das Mulheres no Iraque; e, por fim, (4) A Interpretação dos Movimentos das Mulheres do Iraque em Notícias: uma Análise dos Movimentos das Mulheres do Iraque em notícias: uma Análise de Discurso do período de 2003 a 2013. 


\section{ABORDAGEM CONCEITUAL}

\subsection{A CONSTRUÇÃO DO DISCURSO ORIENTALISTA ${ }^{5}$}

O Orientalismo, de acordo com Edward Said em seu célebre livro "Orientalismo - $O$ Oriente Como Invenção do Ocidente" de 1978, é composto por representações culturais que acontecem entre grupos sociais ou países e refletem as relações de poder existentes entre eles. Portanto, quanto maior a desigualdade entre as partes, maior a distorção da imagem criada e assimilada por aqueles que detêm mais poder sobre os demais (Said, 1996: 15). O Oriente Médio é um dos maiores exemplos dessas relações, no qual o Ocidente cria o Oriente como um reflexo seu, a-histórico e desprovido de identidade, além de o separar por fronteiras geográficas imaginárias - instituindo a noção de "nós" (europeus) e "eles" (todos os outros).

Nessa perspectiva, segundo o autor, deve-se compreender que o Orientalismo se articula na sociedade de uma maneira organizada e de acordo com o contexto histórico, mantendo um diálogo fortemente estabelecido com a cultura dominante que o cerca - antes que qualquer consolidação estatal fosse feita na região, ocorreram as primeiras incursões coloniais, segundo Lisa Anderson (1987) e Fred Halliday (2005). Portanto, na contemporaneidade, o Oriente Médio tem sido vinculado diretamente com "a economia do petróleo e a dicotomia simplista entre Israel democrático e amante da liberdade e os árabes maus, totalitários e terroristas" (Said, 1996: 38), intensificando as dificuldades de uma compreensão isenta de estereótipos. Esse contexto denota, de acordo com o autor, as teias de racismo e propagação de ideologias desumanizadoras acerca do árabe ou muçulmano, deixando-o "acorrentado a um destino que o fixa e o condena a uma série de reações" (Said, 1996: 291). Para Said (1996), a reflexão, o debate e a argumentação racional foram substituídos por ideias abstratas e que embasam a excepcionalidade americana ou ocidental, não contemplando o contexto e desprezando as demais culturas.

\subsection{TEORIA FEMINISTA TRANSNACIONAL}

O Feminismo Transnacional, conforme Margaret McLaren explica em seu livro "Decolonizing Feminism: Transnational Feminism and Globalization" (2017), está diretamente associado às perspectivas decoloniais que procuram desafiar as teorias dominantes - nas esferas políticas, de conhecimento, de linguagens e de poder -, propondo novas formas de abordagem para os problemas contemporâneos e promovendo uma libertação das estruturas coloniais. Segundo McLaren (2017), as feministas transnacionais estabelecem que as principais estruturas que moldam as relações de poder na sociedade são o capitalismo, o racismo e as questões de gênero. Nesse sentido, uma análise feminista transnacional deve

\footnotetext{
${ }^{5}$ Ressaltamos que o Orientalismo pode ser definido tanto como teoria quanto como discurso. Nesse artigo daremos enfoque aos discursos orientalistas.
} 
se voltar também para examinar como movimentos sociais e políticos são baseados em classe e geram, em si mesmos, lócus de poder (Campt, 2011: 132).

Para além da interseccionalidade entre essas articulações, Mariana Chaise (2016) defende que, através dessa perspectiva, há uma necessidade de "reconhecimento das assimetrias globais e das hierarquias de poder entre países" (Chaise, 2016: 1029). Simidele Dosekun (2015) aponta que o "Ocidente há muito tempo representou-se como um lugar de progresso e modernidade para as mulheres", e que as mulheres Ocidentais poderiam salvar as demais.

O feminismo transnacional, assim, surge com o intuito de dar uma resposta ao universalismo - defendido principalmente pelo Ocidente, provocando a absorção de ideias que emanam homogeneizações acerca de significados como liberdade, igualdade, direitos e emancipação (Shih apud Rupa Oza, 2016: 841). Principalmente tendo em vista que a figura da "Mulher do Terceiro Mundo" é apresentada como unidimensional (Dosekun, 2015: 962). Nesse sentido, Chaise (2016) - citando Lila Abu-Lughod e Chandra Mohanty, entre outras autoras - ressalta que essa perspectiva é essencial para criticar o discurso do Orientalismo de Gênero, pois possibilita a sua abordagem dentro de um contexto cultural, com enfoque histórico e sem pretensões universalistas.

\section{QUESTÃO DAS MULHERES DO ORIENTE MÉDIO}

O discurso orientalista proferido pelo Ocidente, principalmente pelos Estados Unidos durante o período de 2003 a 2013, foi formulado com a intenção de legitimar ações e projetos aplicados ao Oriente Médio. A região, no entanto, possuía (e ainda possui) realidades diversas, que fogem dessas interpretações. A existência dessa dicotomia entre realidades e interpretações não apenas influenciou como também legitimou atitudes violentas para com as mulheres do Oriente Médio (Chaise, 2016: 1027). Essa complexidade dicotômica é abafada por uma interpretação simplista, adequando a diversidade nos estereótipos criados ao longo de séculos a fim de opor a "mulher oriental" à mulher ocidental (Mohanty, 1997 apud Chaise, 2016: 1028).

É importante a compreensão da teorização de Orientalismo, com o intuito de entender de que forma esse discurso se constrói e como impacta na vida dessas mulheres. Embora haja críticas à forma como Said e outros teóricos estabelecem o estudo de gênero e sexualidade como um subcampo de análise na Teoria Orientalista (Meyda Yeğenoğlu apud Abu-Lughod, 2001: 103), a tese de Said oferece um modelo de estudos que tem enfoque nos emaranhados políticos, podendo ser muito bem utilizada em estudos feministas do Oriente Médio - possibilitando uma crítica mais aberta e consciente às múltiplas formas de injustiças que encontram (Abu-Lughod, 2001: 112). Por exemplo, Abu-Lughod (2013) também apresenta que a literatura criada sobre as mulheres muçulmanas toma um aspecto pornográfico, com a "objetificação dos sujeitos e a descrição de violência, força sexual, 
e escravidão" (Abu-Lughod, 2013: 103, tradução nossa ${ }^{6}$ ) diretamente ligada a aspectos de dominação, colonial e/ou racial. As mulheres muçulmanas viram um "corpo colonial", que para Gomes (2013):

[...] é um corpo construído como alvo da opressão dos colonizadores, em uma intersecção de raça, gênero, sexualidade e classe (exploração do trabalho). 0 'corpo colonial' é, sobretudo, um corpo visto como disponível. (Gomes, 2013: 48).

Isso pode ser mais uma vez evidenciado através das contribuições da autora Meyda Yeğenoğlu, em seu livro "Colonial Fantasies: towards a feminist reading of Orientalism"7 (1998), o qual enfatiza a questão do véu e como ele é fantasiado pelos ocidentais como uma barreira que os impede de adentrar nos mistérios e interioridade do Oriente. A partir disso, a autora destaca o caso das mulheres argelinas, vistas como aquelas que se escondem atrás do véu, permitindo que o colonialismo formasse uma doutrina política em torno disso - os colonizadores achavam que, para fragmentar a sociedade, deviam conquistar as mulheres primeiro.

Assim, o véu passa a ser descrito como não apenas um problema para as mulheres muçulmanas, mas como o maior deles, criando uma imagem de mulher oprimida pela sua religião. De acordo com Abu-Lughod (1992), os liberais por vezes confessam sua surpresa ao perceber que as mulheres afegãs não abandonaram suas burqas após a retirada do Talibã. "Nós deveríamos querer justiça e direitos para as mulheres, mas podemos aceitar que podem existir diferentes ideias sobre justiça e que diferentes mulheres podem querer, ou até mesmo escolher, diferentes futuros daqueles que nós vemos como melhor?" (Abu-Lughod, 2013: 43, tradução nossa) ${ }^{8}$.

Assim, o "Orientalismo de Gênero" (Chaise, 2016: 1027) configura o cenário no qual as mulheres muçulmanas e árabes se encontram em uma dupla luta: a opressão dentro das próprias comunidades, e as políticas orientalistas internacionais (Abu-Lughod, 2013: 79), e precisam lutar com representações falaciosas sobre si. É nesse contexto que a Teoria Feminista Transnacional, proposta por autoras como Abu-Lughod (2013), Mohanty (2002), McLaren (2017), entre outras, apresenta-se como uma alternativa de análise capaz de abarcar a complexidade de estruturas existentes, pois foca na importância das interseccionalidades de gênero, raça e classe, assim como o contexto assimétrico em que todos os Estados se encontram; além de analisar as causas das opressões de gênero em contextos culturais diferentes, negando uma compreensão universal e a-histórica (Chaise, 2016).

Nesse sentido, de acordo com Abu-Lughod (2013) e Dosekun (2015), o discurso pela salvação das mulheres árabes que foi amplamente utilizado desde o início da Guerra ao Terror, fazia uso de um pós-feminismo imperialista e neoliberal, em que as mulheres do Sul

\footnotetext{
6 "objectification of subjects and its depiction of violence, sexual force, and bondage." (Abu-Lughod, 2013: 103)

7 Fantasias Coloniais: rumo a uma visão feminista do Orientalismo, tradução nossa.

8 We should want justice and rights for women, but can we accept that there might be different ideas about justice and that different women might want, or even choose, different futures from ones that we envision as best? (Abu-Lughod, 2013: 43)
} 
seriam aquelas a serem empoderadas - assim, abrindo espaço para que os Estados possam operacionalizar essa retórica para fins de agendas desenvolvimentistas e intervencionistas. Como exemplo, ainda no ano de 2010, Clinton discursou para a Comissão sobre o Status da Mulher nas Nações Unidas, afirmando que "Presidente Obama e eu acreditamos que a subjugação das mulheres é uma ameaça à segurança nacional dos EUA" (Toor apud Oza, 2016: 839, tradução nossa) ${ }^{9}$.

Jasmin Zine (2006) expõe que os discursos estadunidenses na época classificam a sociedade árabe muçulmana como anacrônica, que perde seu espaço num tempo de modernidade. Esses discursos mantiveram-se no estereótipo da mulher árabe: a burqa, a religião, a opressão sofrida pelas mãos dos homens árabes. São discursos racializados que servem para classificar os muçulmanos como bárbaros e não civilizados, usando da narrativa do progresso e da modernidade para ocupar o Iraque como um gesto humanitário. Muitas vezes se trata da visão de "homens brancos salvando mulheres marrons de homens marrons" (Spivak apud Abu-Lughod, 2013: 33, tradução nossa) ${ }^{10}$. Visto isso, e percebendo a falácia dos discursos orientalistas, podemos destacar como central a questão das mulheres na Guerra ao Terror, vendida incansavelmente pelos Estados Unidos.

\section{OS MOVIMENTOS DAS MULHERES DO IRAQUE AO LONGO DA HISTÓRIA}

Os Movimentos das Mulheres no Iraque sempre estiveram muito envolvidos em todas as agitações políticas que moldaram a história do país. De acordo com Nadje Al-Ali (2012: 105), surgidos no início do século XX, esses movimentos se estabeleceram e foram oferecendo enfoque especial para as questões de desigualdade e injustiça social baseadas no gênero. Por essa razão, as meninas e mulheres iraquianas tiveram, historicamente, mais direitos que a maioria das outras mulheres da região do Oriente Médio - mas isso não significa que elas não tenham sofrido abusos.

Durante o período de protetorado do Reino Unido no Iraque, não havia interesse em desenvolver os direitos das mulheres (Neshat, 2003: 56). Nesse contexto, elas começaram a se organizar social e politicamente, participando de forma ativa contra a ocupação colonial. Em 1923, foi criado o Women's Awakening Club, o qual participou dos movimentos nacionais de independência. Mais tarde, em meados da década de 1940, a Women's League Against Nazism and Fascism lutava e apoiava ideias democráticas e se dedicava fortemente à erradicação do analfabetismo das mulheres (Al-Ali, 2012: 105-107). Já a Iraqi Woman's Union esteve estabelecida sob a monarquia e exercia trabalho voluntário, além de se voltar para a educação das mulheres e networking entre diversas organizações de mulheres (Al-Ali, 2012:107). A Iraqi Woman's League, por sua vez, cresceu consideravelmente nos anos 1950 e era ativa na questão de trabalho humanitário e mobilização política (Al-Ali, 2012: 107).

\footnotetext{
9 "President Obama and I believe that the subjugation of women is a threat to the national security of the United States." (Toor apud Oza, 2016: 839)

10 "white men saving brown women from brown men." (Spivak, 1988, apud Abu-Lughod, 2013: 33)
} 
No período pós-proclamação da República, o regime revolucionário de al-Karim Qasim aprovou o conjunto de leis familiares mais progressivas da região, o Personal Status Code (1959). Porém, os membros do Partido Ba'ath instalaram um golpe bem-sucedido, a partir do qual os robustos movimentos das mulheres passaram por um processo de desmonte, assim como as políticas prevalecentes do Iraque (Al-Ali, 2012: 107-108). A emancipação das mulheres se tornou um ponto chave na retórica das políticas nacionais, sendo utilizadas como fontes de influência ideológica para as próximas gerações e subsequente aumento das bases de apoio (Al-Ali, 2012: 108-112). Assim, o governo estabeleceu a General Federation of Iraqi Women e tornou um crime a filiação das mulheres em quaisquer outras organizações do gênero. Essa possuía limitado poder de independência política, mas conseguiu promover conquistas para as mulheres - na educação, na saúde, na participação na vida pública, entre outros - até o momento em que o regime voltou suas normas e políticas para um viés mais conservador. (Al-Ali, 2012: 108-112).

Com a Guerra do Golfo de 1991, a posição das mulheres na sociedade começou a deteriorar de forma drástica. Um dos fatores mais determinantes para isso foi Saddam Hussein ter utilizado as tradições islâmicas e tribais conservadoras como uma forma de consolidar seu poder (Human Rights Watch, 2003). Além disso, as sanções impostas pelas Nações Unidas tiveram um forte impacto na vida dessas mulheres no tangente à educação, saúde e economia. Essa soma de fatores resultou em impactos negativos aos direitos das mulheres, sendo um verdadeiro retrocesso no seu status legal, no sistema criminal de justiça e nas leis de status pessoal.

Já no contexto da intervenção militar dos Estados Unidos no Iraque, em 2003, as mulheres passaram por mais um período de instrumentalização pois, entre outras razões - interesses econômicos, preocupações geopolíticas, desejo de projeção de poderio militar e dominação imperial, e não pela preocupação iminente com os direitos humanos (Kramer; Michalowski apud Banwell, 2015: 708) -, a guerra foi justificada por uma retórica estadunidense de preocupações com os abusos dos direitos das mulheres e a necessidade de levar liberdade para elas - que se tornou uma parte central do discurso da Guerra ao Terror (Neshat, 2003: 59; Khalid, 2011: 5).

Essas justificativas eram embasadas no discurso orientalista e se apoiam em binarismos (livres e oprimidas, civilizados e bárbaros), colocando a violência irracional e a misoginia como algo intrínseco do mundo "deles" (Ho, 2010; Khalid, 2011: 7). Essa retórica pode ser desmascarada como falaciosa, especialmente quando se leva em consideração as atitudes dos soldados e soldadas estadunidenses no Iraque, diretamente guiados pelo discurso orientalista, como foi o caso da prisão de Abu Ghraib (Nusair, 2008). Além de falaciosa, essa retórica projetou as mulheres como passivas no ambiente em que estão inseridas, e também desconsiderou o fato de que as mulheres do Iraque possuíam altos índices de participação na vida pública (Ho, 2010). 
Ainda, Huibin Amelia Chew (2008: 90) vai mais além, explicando que na realidade a invasão do Iraque restringiu o acesso público das mulheres na região. No período de 2003 a 2013, pode ser observado que as promessas de direitos a essas mulheres não foram cumpridas e elas foram marginalizadas nos processos políticos e de reconstrução do Iraque (Khalid, 2011: 14). De acordo com Stacy Banwell (2015: 706), o cenário pós-invasão exacerbou problemas já existentes e até criou outros no tangente à instabilidade social, econômica e ataques violentos - violência sexual, abduções, prostituição, ameaças e assassinatos de ativistas -, o oposto do que fora prometido.

Nesse contexto, a partir de 2003, Nadje Al-Ali e Nicola Pratt (2009) colocam que diversas organizações e ações afirmativas começaram a se propagar pelo Iraque - como o National Council of Women (NWC), o Iraqi Women's Higher Council (IWHC), o Iraqi Independent Women's, a Society for Iraqi Women for the Future e a Iraqi Women's Network (Al-Ali, 2012: 114). Muitas dessas organizações foram organizadas pela elite, financiadas por partidos políticos ou ativistas independentes. $\mathrm{O}$ que demonstra que esses movimentos nem sempre são iniciados por elas - alguns deles (como do período imperial e de Saddam Hussein) são impostos por padrões "de cima para baixo" e não puramente conquistados -, mas mesmo assim são uma forma essencial de institucionalização dos seus direitos e necessidades, e uma forma de lutar contra as violações cometidas (Neshat, 2003: 57).

Para Neshat (2003), os movimentos das mulheres são vitais para sua organização política e social - principalmente na reconstrução do Iraque -, podendo afetar tanto as vidas das mulheres locais, como também das mulheres de toda a região. Ainda, vale ressaltar a mobilização política das mulheres pelos seus direitos e por uma maior participação política, a partir da qual conquistaram uma cota de $25 \%$ para mulheres na Assembleia do país (Al-Ali, 2012: 114-118). No entanto, a existência desses movimentos é percebida pelo Ocidente?

\section{A INTERPRETAÇÃO DOS MOVIMENTOS DAS MULHERES DO IRAQUE EM NOTÍCIAS: UMA ANÁLISE DE DISCURSO DO PERÍODO DE 2003 A 2013}

Como aponta Mahmood Monshipouri (2004: 192), os movimentos pelos direitos das mulheres não surgem apenas no Ocidente. A partir da revisão das pesquisas feitas, principalmente por Al-Ali (2012) e Neshat (2003), é possível perceber que o movimento das mulheres iraquianas sempre foi muito presente na sociedade. Essa constatação, no entanto, é oposta ao discurso que se tem das mulheres iraquianas no Ocidente, como vimos nas seções anteriores. Assim, tendo o intuito de auxiliar nesse debate, procuramos compreender como o discurso orientalista influencia na interpretação do movimento das mulheres iraquianas através da análise de notícias de jornais estadunidenses.

Dessa forma, utilizamos da metodologia de análise de discurso, selecionando 20 notícias dentre as cinco principais fontes de notícias dos Estados Unidos no período de 2003 a 2013. O período de análise foi escolhido com base na Guerra ao Terror, a fim de 
perceber como, e se, as mulheres iraquianas e seus movimentos sociais e políticos eram interpretados pela mídia estadunidense. A seleção das fontes foi feita de acordo com o ranking desenvolvido pelo think tank Pew Research Center, em que um estudo na área de Jornalismo e Mídia sobre "U.S. MEDIA POLARIZATION AND THE 2020 ELECTION: A NATION DIVIDED"11, aponta que os adultos estadunidenses, como um todo, tendem a confiar mais nas emissoras de notícias ABC News (48\%), CNN (47\%), NBC News (47\%), CBS News (45\%) e Fox News (43\%). Para a escolha das notícias dentro desses canais foram utilizadas três palavras chaves em inglês: "women's movement in Iraq", "iraqi women", "women iraq".

Analisando as notícias, é possível perceber que um número baixo de reportagens é mantido durante todo o período - o ano com maior quantidade de notícias encontrado foi 2008, ano em que houve um aumento no número de mulheres bomba no país, e também o ano em que houve tentativa de eleições (NBC, 04/01/2008 ${ }^{12}$; NBC, 06/10/2008 ${ }^{13}$ ). Por outro lado, não foram encontradas notícias nos anos de 2011 e 2012.

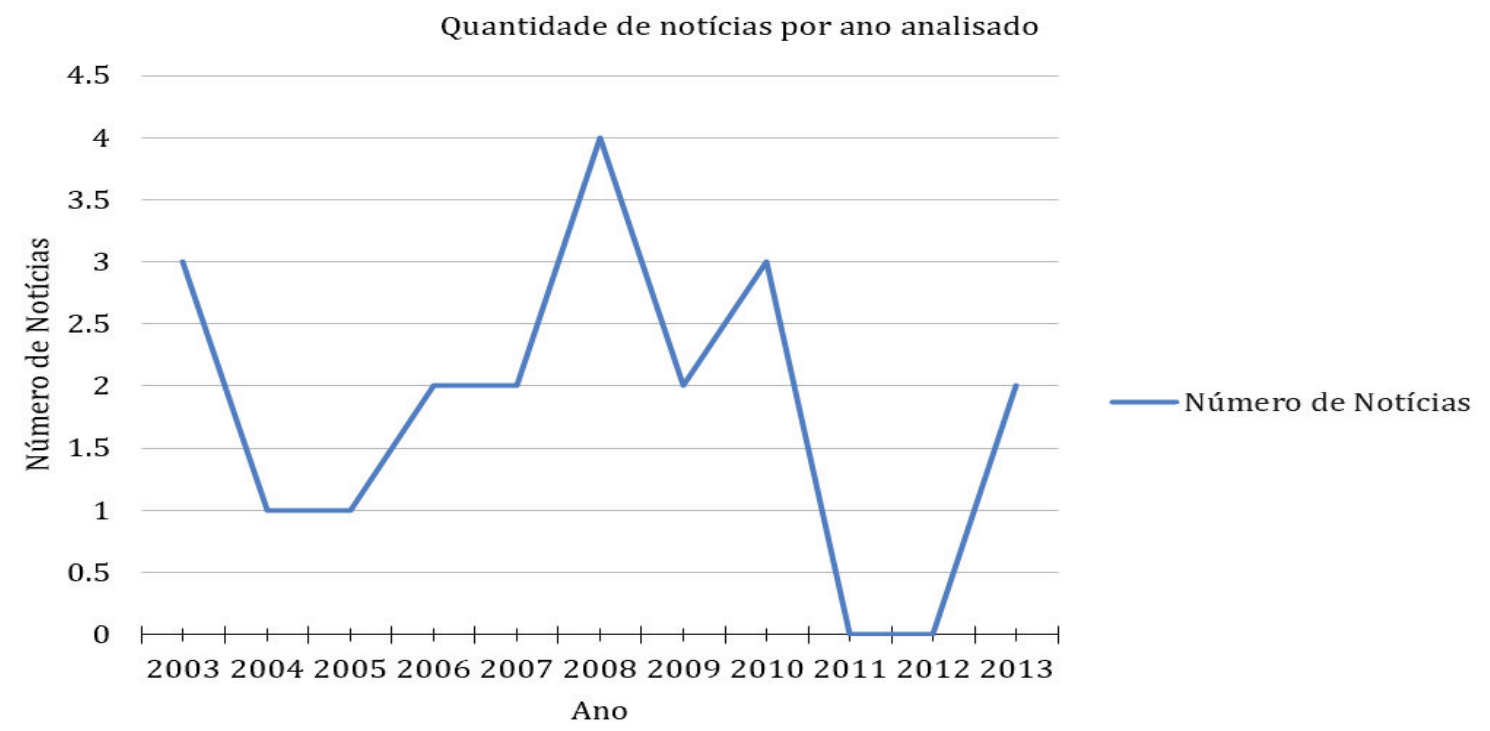

Gráfico 1 - Quantidade de notícias por ano analisado. Confecção própria.

Contrário às expectativas de que a Fox News, jornal que mais apoiou o governo Bush em sua invasão ao Iraque em 2003, ou a CNN, jornal que mais noticiou a guerra, (Harmon e Muenchen, 2009), fossem ter um grande número de notícias, apenas 1 foi encontrada

\footnotetext{
${ }^{11} \mathrm{O}$ estudo foi feito por MARK JURKOWITZ, AMY MITCHELL, ELISA SHEARER e MASON WALKER, tendo sido publicado dia 24 de janeiro de 2020, com o objetivo de mostrar o nível de confiança nas diferentes fontes de notícias pela população estadunidense, dividindo ela como um "all U.S. adults; Democrat/Lean Dem; Republican/Lean Rep". Para o nosso estudo, foi utilizada a porcentagem analisada para "all U.S. adults". ${ }^{12}$ IRAQI Militants Turn to Women for Suicide Attacks. NBC, Nova Iorque, 04 jan. 2008. Disponível em: <http:// www.nbcnews.com/id/22510553/ns/world_news-mideast_n_africa/t/iraq-militants-turn-women-suicideattacks/\#.Xpi518hKjIV>. Acesso em: 16/04/2020.

${ }^{13}$ IRAQI women fear going public as candidates. NBC, Nova Iorque, 06 out. 2008. Disponível em: <http:// www.nbcnews.com/id/27052931/ns/world_news-mideast_n_africa/t/iraqi-women-fear-going-publiccandidates/\#.Xpi5qchKjIW>. Acesso em: 16/04/2020.
} 
na primeira emissora e 4 na segunda. Dentre as 20 notícias analisadas, a empresa ABC News foi responsável por 6 (30\%) das publicações nos 10 anos analisados, seguida por 5 da NBC News (25\%), 4 da CBS News (20\%) e da CNN (20\%), e 1 da Fox News (5\%). Ou seja, a emissora com maior nível de confiança (ABC News) foi aquela com o maior número de notícias.

Nesse sentido, o conceito de "framing" trazido por Harmon e Muenchen (2009: 13) se torna útil para compreender o foco da nossa análise. "Framing", isto é, a escolha de algumas partes de eventos e problemas para promover uma certa interpretação, é utilizado pela mídia para delinear sobre quais sujeitos deve-se pensar. No caso da Guerra do Iraque, houve um esforço coordenado por parte do governo e da mídia - como será analisado em seguida - para focar em alguns problemas (como armas de destruição em massa, violação de direitos humanos, opressão das mulheres por parte do governo do Saddam Hussein), promovendo, assim, uma interpretação parcial e demonizada do Iraque, seus habitantes, as mulheres iraquianas, e os seus direitos (Harmon e Muenchen, 2009: 14).

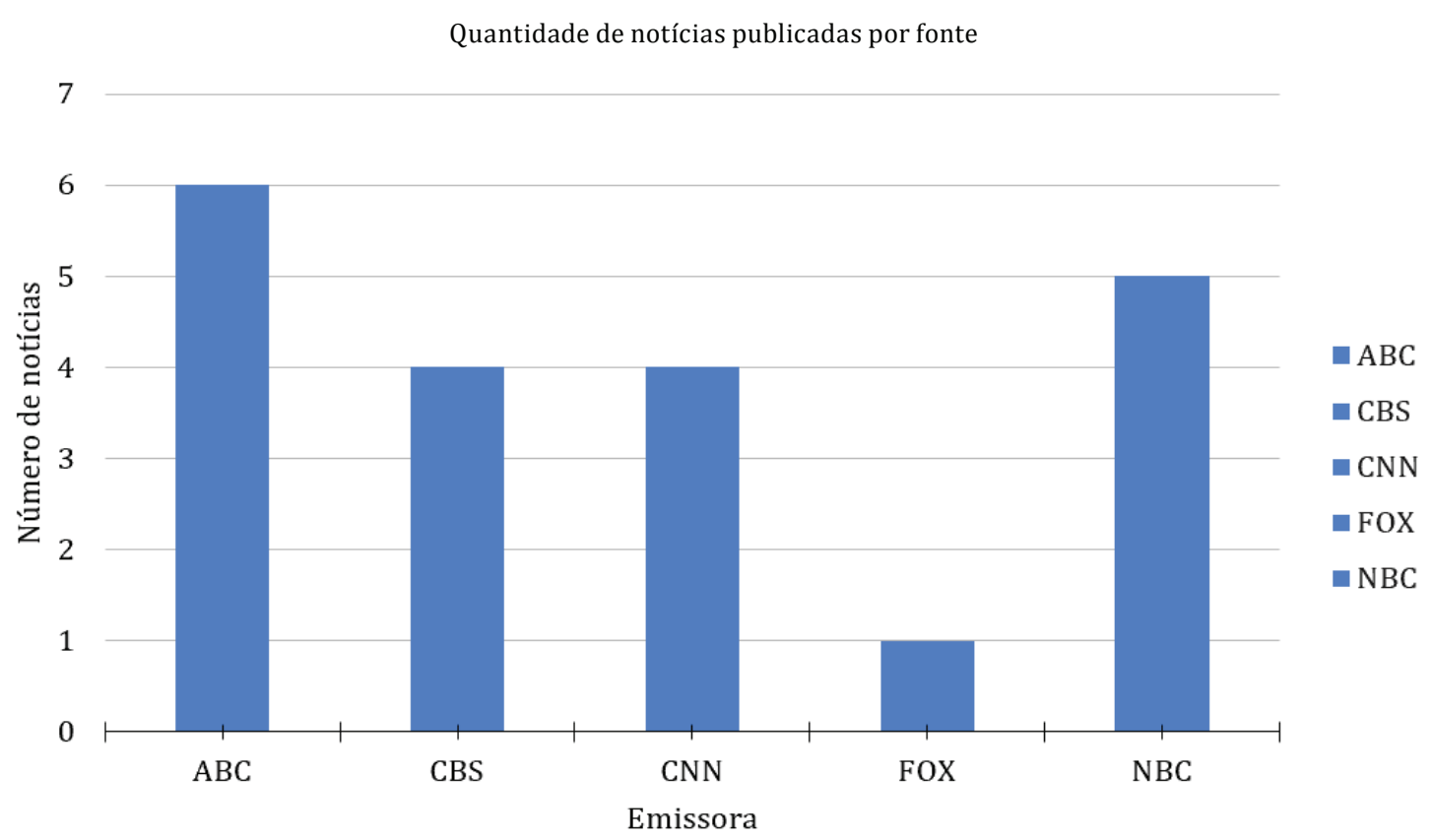

Gráfico 2 - Quantidade de notícias publicadas por fonte. Confecção própria.

Para compreender empiricamente como esse "framing" ocorreu no caso das mulheres do Iraque, organizamos quatro categorias de análise de discurso da relação entre o discurso orientalista e a interpretação dos movimentos das mulheres do Iraque. As categorias de análise se dividem em: (1) religião; (2) "homens brancos salvando mulheres marrons de homens marrons" ${ }^{14}$; (3) abusos e violações; e, (4) participação política. A decisão por essas categorias surgiu após uma análise inicial das notícias, em que percebemos os vieses

\footnotetext{
${ }^{14}$ Referência a citação de Spivak mencionada anteriormente no artigo. "White men saving brown women from brown men"(Spivak apud Abu-Lughod, 2013: 33)
} 
principais que elas seguiam. Ressaltando que cada notícia pode aparecer em mais de uma categoria simultaneamente, a classificação individual delas - baseada no teor da notícia -, assim como sua manchete, pode ser vista no quadro 1 abaixo. A partir do quadro, podemos perceber que das 20 notícias, 13 (65\%) abordam a questão da participação das mulheres. A questão religiosa apareceu em 10 (50\%) das notícias. Com base nisso, partimos para uma análise discursiva mais aprofundada das notícias, com o intuito de entender como as emissoras estavam retratando essa temática.

Quadro 1 - Síntese da análise

\begin{tabular}{|c|c|c|c|}
\hline Fonte & Data & Manchete & $\begin{array}{l}\text { Categorias de } \\
\text { Análise* }\end{array}$ \\
\hline $\mathrm{ABC}$ & 06/01/2006 & $\begin{array}{l}\text { Iraqi Women Grateful for U.S. } \\
\text { Campaign }\end{array}$ & 2,3 e 4 \\
\hline $\mathrm{ABC}$ & $07 / 01 / 2006$ & $\begin{array}{c}\text { Some Fear Loss of Women's Rights } \\
\text { in Iraq }\end{array}$ & 1 e 4 \\
\hline $\mathrm{ABC}$ & $07 / 01 / 2006$ & $\begin{array}{c}\text { Iraqi Women Train as Police } \\
\text { Officers }\end{array}$ & 2 \\
\hline $\mathrm{ABC}$ & $10 / 05 / 2007$ & $\begin{array}{c}\text { Harsh Reality for Many Iraqi } \\
\text { Women }\end{array}$ & 2 e 3 \\
\hline $\mathrm{ABC}$ & $12 / 02 / 2009$ & $\begin{array}{l}\text { Iraqi Women Targeted by } \\
\text { Campaign of Violence }\end{array}$ & 1,2 e 3 \\
\hline $\mathrm{ABC}$ & $25 / 03 / 2009$ & $\begin{array}{c}\text { Iraqi Women Can Now Say No to } \\
\text { Hijab or Head Scarf }\end{array}$ & 1 e 3 \\
\hline CBS & $15 / 07 / 2003$ & A Call To Protect Iraqi Women & 2 e 3 \\
\hline CBS & $16 / 02 / 2004$ & Strong, Smart \& Female In Iraq & 1 e 4 \\
\hline CBS & 03/03/2010 ok & $\begin{array}{c}\text { Diverse Iraqi Women Seek } \\
\text { Political Parity }\end{array}$ & 2 e 4 \\
\hline CBS & $17 / 08 / 2010$ & $\begin{array}{c}\text { Iraqi Women: Hearing From a } \\
\text { Forgotten Voice }\end{array}$ & 1 e 4 \\
\hline CNN & 2008 & $\begin{array}{l}\text { Women's rights activist beheaded } \\
\text { in Iraq }\end{array}$ & 3 \\
\hline CNN & $26 / 06 / 2007$ & Fighting for women's rights in Iraq & 1,3 e 4 \\
\hline CNN & 09/03/2010 & $\begin{array}{c}\text { Iraqi activist: Women's rights } \\
\text { must be focus for new } \\
\text { parliament }\end{array}$ & 4 \\
\hline CNN & $18 / 03 / 2013$ & $\begin{array}{c}\text { Why women are less free } 10 \text { years } \\
\text { after the invasion of Iraq }\end{array}$ & 3 e 4 \\
\hline FOX & $11 / 02 / 2003$ & $\begin{array}{l}\text { Iraqi Women Brutalized by } \\
\text { Saddam Published February }\end{array}$ & 3 e 4 \\
\hline
\end{tabular}




\begin{tabular}{|c|c|c|c|}
\hline Fonte & Data & Manchete & $\begin{array}{c}\text { Categorias de } \\
\text { Análise* }\end{array}$ \\
\hline NBC & $02 / 08 / 2005$ & $\begin{array}{c}\text { Iraqi Women Seek Constitutional } \\
\text { Rights }\end{array}$ & 1,2 e 4 \\
\hline NBC & $04 / 01 / 2008$ & $\begin{array}{c}\text { Iraqi Militants Turn to Women for } \\
\text { Suicide Attacks }\end{array}$ & 1,2 e 4 \\
\hline NBC & $13 / 07 / 2008$ & $\begin{array}{c}\text { Iraqi women join security } \\
\text { program in Diyala }\end{array}$ & 1,2 e 4 \\
\hline NBC & $06 / 10 / 2008$ & $\begin{array}{c}\text { Iraqi women fear going public as } \\
\text { candidates }\end{array}$ & $1,2,3$ e 4 \\
\hline NBC & $12 / 11 / 2013$ & $\begin{array}{c}\text { Iraqi women lament costs of U.S } \\
\text { invasion }\end{array}$ & 1 e 3 \\
\hline
\end{tabular}

*1 - Religião (11); 2 - "Homens brancos salvando mulheres marrons de homens marrons” (10); 3 - Abusos e Violações (11); 4 - Participação das Mulheres (13).

Quadro 1 - Síntese de análise. Confecção própria.

Em relação à religião, primeira categoria de análise, e um dos pontos mais mencionados dentre as 20 notícias analisadas, engloba-se o Islamismo, as leis islâmicas, sharia e leis tribais, assim como apontamento de vestimentas religiosas. Ao falar da nova democracia iraquiana, normalmente o contexto se volta para como as mulheres foram deixadas de lado em detrimento de líderes religiosos e tribais (CNN, 26/06/2007) ${ }^{15}$. Além disso, é retratado que há um receio muito grande por parte das mulheres que a lei islâmica seja adotada, pois ela limitaria direitos que elas conquistaram, e dificultaria a sua participação na vida social e política (Johnston, CBS, 16/02/2004).

Já em uma notícia de 2010, é reportado que o uso de leis tribais é feito com mais frequência do que das leis oficiais do país, resultando na marginalização das mulheres no país (Omar, CBS, 17/08/2010). A ABC News, por exemplo, menciona com frequência a religião islâmica, destacando-a como um desafio a ser superado. A presença de mulheres atuantes em partidos religiosos é colocada como o grande desafio para que outras ativistas iraquianas consigam mobilizar a Assembleia do país em favor da garantia dos direitos das mulheres já existentes e para a conquista de outros (ABC, 07/01/2006) ${ }^{16}$.

Além disso, ao noticiar sobre uma melhora na segurança do país, o foco da reportagem se volta para o fato de agora as mulheres não serem pressionadas ao uso do hijab (Rashid, ABC, 25/03/2009). Em uma notícia publicada pela emissora NBC em 13/07/2008 ${ }^{17}$, cujo

\footnotetext{
${ }^{15}$ FIGHTING for women's rights in Iraq. CNN, Atlanta, 26 jun. 2007. Disponível em: <https://edition.cnn. com /2007/WORLD/meast/06/26/pysk.mohammed/index.html>. Acesso em: 18/04/2020

${ }^{16}$ SOME Fear Loss of Women's Rights in Iraq. $A B C$, Nova Iorque, 07 jan. 2006. Disponível em: <https:// abcnews.go.com/WNT/IraqCoverage/story?id=666790 >. Acesso em: 19/04/2020.

${ }^{17}$ IRAQI women join security program in Diyala. NBC, Nova Iorque, 13 jul. 2008. Disponível em: <http:// www.nbcnews.com/id/25663110/ns/world_news-mideast_n_africa/t/iraqi-women- join-security-programdiyala/\#.Xpi55chKjIW>. Acesso em: 17/04/2020.
} 
foco era a inserção das mulheres no trabalho de segurança, a primeira frase descreve seu uso de abayas. Em outra notícia, enquanto uma mulher descreve sua insegurança no país, a notícia aponta seu uso de hijab e abaya (al-Salhy; Colesk, NBC, 12/11/2013). Como apontam Abu-Lughod (2013) e Yeğenoğlu (1998), o "véu", seja ele um hijab ou abaya, continua sendo um grande foco quando é falado sobre mulheres muçulmanas. Apesar disso, duas reportagens da $\mathrm{ABC}$ ano de 2009 ressaltam que a invasão do Iraque coordenada pelos EUA, em 2003, resultou no surgimento de grupos religiosos mais extremistas, desencadeando segregações religiosas que aumentaram a perseguição violenta de mulheres e meninas (Rashid, ABC, 25/03/2009; McMullen, ABC, 12/02/2009).

Visto a retórica salvacionista abordada antes, a nossa segunda categoria de análise foca em "homens brancos salvando mulheres marrons de homens marrons". Acreditamos ser importante ressaltar a existência dessa perspectiva nas notícias, sendo que ela apresenta a questão que Said (1996) aponta da criação do "outro" inferior. Harmon e Muenchen (2009) afirmam que, para fazer o "framing" da Guerra do Iraque, foi construída a imagem de EUA e aliados como heróis confrontando vilões para não apenas derrotá-los, mas liberar seu povo. A maioria das notícias destacam o dever dos EUA e das tropas americanas de proteger as mulheres e a população iraquiana (al-Salhy; Colesk, NBC, 12/11/2013; Bryson, CBS, 15/07/2003; Omar, CBS, 17/08/2010).

Isso pode ser visto com clareza nas notícias da ABC, seja em relação a diminuição das forças da Al Qaeda em razão da estratégia estadunidense contrainsurgência (McMullen, ABC, 12/02/2009), ou no discurso de garantia dos direitos das mulheres e protegê-las da instabilidade e violência - em 2006, o próprio título da notícia, "Iraqi Women Grateful for US Campaign", traz um teor de salvador branco (ABC, 06/01/2006) ${ }^{18}$. 0 mesmo ocorre quando da criação das "Filhas do Iraque" - mulheres treinadas para revistar outras mulheres em checkpoints, a fim de prevenir mulheres bomba (NBC, 13/07/2008) ${ }^{19}$.

De acordo com uma entrevistada, essas mulheres queriam ser como as policiais nos EUA, um sonho que elas queriam que se tornasse realidade, a fim de usar todo o poder que têm para ajudar seu país. Outro aspecto, acerca do fechamento do programa de treinamento de mulheres para oficiais de polícia, é afirmado que os EUA estavam com as orelhas cheias (Babarovic, ABC, 07/01/2006) de ouvir preocupações das graduandas acerca do fechamento do programa e que, após a visita de um grupo de mulheres soldado norte-americanas, foi colocado um fim positivo nessa conversa.

Uma notícia de 02/08/2005 ${ }^{20}$ da NBC aponta também a preocupação dos EUA que a Lei Islâmica cerceie os direitos das mulheres, tendo conexão com seu discurso de promoção dos Direitos Humanos, o qual ajudou a legitimar a Guerra ao Terror do Iraque. Por

\footnotetext{
${ }^{18}$ IRAQI Women Grateful for U.S. Campaign. $A B C$, Nova Iorque, 06 jan. 2006. Disponível em: <https:// abcnews.go.com/2020/story?id=123738\&page=1>. Acesso em: 18/04/2020.

${ }^{19}$ Vide nota de rodapé número 17 (NBC, 2008).

${ }^{20}$ IRAQI Women Seek Constitutional Rights. NBC, Nova York, 02 de ago. 2008. Disponível em: <http://www. nbcnews.com/id/8799295/ns/world_news-mideast_n_africa/t/iraqi-women-seek-constitutional-rights/\#. Xpi5gMhKjIV>. Acesso em: 17/04/2020.
} 
fim, uma notícia da $\mathrm{ABC}$ traz a complexidade da imposição de direitos e valores ocidentais, colocando a perspectiva de Laura Nader, entre outras, que afirma que direitos e leis não são algo que se possa impor do exterior, principalmente em um país tão plural como o Iraque. Além de afirmar suas preocupações com o uso do discurso dos direitos humanos como meio de imposição de normas ocidentais - uma forma de neocolonialismo (Ghadishah, $A B C, 10 / 05 / 2007$ ) que, muitas vezes, exige mais do que é capaz de cumprir (CBS, $03 / 03 / 2010)^{21}$.

Considerando o cenário de guerra da intervenção, e o discurso estadunidense de defesa das mulheres iraquianas, uma análise sobre abusos e violações se fez necessária, e é nisso que nossa terceira categoria de análise irá se basear. Como apontado por Abu-Lughod anteriormente, precisamos perceber a objetificação dos sujeitos e descrição da violência que podem estar atreladas ao domínio colonial e à ideia de corpo colonial (GOMES, 2013).

Notícias da ABC (06/01/200622; McMullen, 12/02/2009; Rashid, 25/03/2009), CNN (26/06/200723; 2008 ${ }^{24}$ ) e CBS (Bryson, 15/07/2003) retratam como a violência desde 2003 se fez ainda mais presente na realidade das mulheres iraquianas, ressaltando o aumento substantivo de assassinatos, sequestros, estupros, e "honor killings", além de expectativas rígidas quanto ao código de vestuário a ser seguido.

Nesse sentido, destaca-se um caso de "honor killing" conduzido em público e divulgado na internet através de vídeo que, segundo a $\mathrm{ABC}$, despertou a atenção do mundo para esse assunto e, no decorrer da reportagem afirma que "os Estados Unidos está, desesperadamente, tentando forjar um futuro estável no Iraque"25 (Ghadishah, ABC, 10/05/2007, tradução nossa). Para ativistas dos direitos das mulheres, como Yanar Mohammed, fundadora da Organization of Women's Freedom, a luta das mulheres iraquianas é por liberdades que as outras nações tomam como garantidas; ela diz: "nós vemos na televisão centenas de oficiais que dizem ter dado liberdade às mulheres, mas você olha nas ruas - todas as mulheres usam véu (...); elas não podem andar livremente, elas não podem ter sua educação, não podem trabalhar"26 (CNN, 2007, tradução nossa) ${ }^{27}$.

Uma das notícias da NBC aponta sobre a violência contra as pessoas que candidatam-se a cargos públicos, salientando que "o problema é mais significativo para mulheres, que sofreram ataques simplesmente por usarem maquiagem ou se recusarem a utilizar

\footnotetext{
${ }^{21}$ DIVERSE Iraqi Women Seek Political Parity. CBS, Nova Iorque, 03 mar. 2010. Disponível em: <https:// www. cbsnews.com/news/diverse-iraqi-women-seek-political-parity/>. Acesso em: 14/04/2020.

${ }^{22}$ Vide nota de rodapé número 18 (ABC, 2006).

${ }^{23}$ Vide nota de rodapé número 15 (CNN, 2007).

${ }^{24}$ WOMEN'S rights activist beheaded in Iraq. CNN, Atlanta, 2008. Disponível em: <https://edition.cnn. com/2008/WORLD/meast/12/18/iraq.arrests/>. Acesso em: 19/04/2020.

25 "the United States is desperately trying to forge a stable future in Iraq" (Ghadishah, ABC, 10/05/2007).

26 "We see over the television hundreds of officials who say that they have given freedoms to women," Mohammed said. "But you look at the streets -- every single woman is veiled (...); she cannot move freely, she cannot go to her education, cannot go to work." (CNN, 2007)

${ }^{27}$ Vide nota de rodapé número 15 (CNN, 2007).
} 
lenços na cabeça e vestes pretas da cabeça aos pés" ${ }^{28}$ (NBC, 06/10/2008, tradução nossa) ${ }^{29}$. Já na única notícia da Fox News (McElroy, 11/02/2003), vemos contradições sobre a afirmação de que as mulheres iraquianas teriam abundantes direitos durante o governo de Saddam Hussein, nela é apontado que: "a mulher iraquiana suportou tortura, assassinato, confinamento, execução, e banimentos, assim como outro(s) na sociedade iraquiana, pelas mãos da gangue criminosa de Saddam Hussein" (McElroy, FOX News, 11/02/2003, tradução nossa ${ }^{30}$; e mesmo assim, um movimento feminista dos Estados Unidos se mostrava receoso em abraçar essa causa e tentar libertá-las dessas opressões. Por último, uma notícia de 2013 traz o melhor exemplo daquilo que Abu-Lughod afirmou: "Ibtisam, 40, foi ferida por uma barra de ferro enquanto fugia de um bombardeio na invasão promovida pelos EUA e foi forçada e ter seu útero cirurgicamente removido. Durante a carnificina que seguiu, a milícia xiita sequestrou e matou seu marido" (al-Salhy; Colesk, NBC, 12/11/2013, tradução nossa) ${ }^{31}$.

A fim de entender se e como a movimentação das mulheres é interpretada, foi necessário analisar qual o teor das notícias quanto à sua atuação dentro da sociedade, que é englobada pela nossa quarta categoria: participação política. Historicamente, as mulheres do Iraque tiveram mais liberdades que as mulheres de países vizinhos, inclusive durante a época secular do regime de Saddam Hussein, reconhecidas como iguais perante a lei (CNN, $26 / 06 / 2007)^{32}$. A esperança das mulheres era a de que um governo recém-eleito pudesse sanar suas necessidades e trazer mudanças para elas - participar ativamente do governo, ter espaço na nova constituição -, mas ela foi frustrada pois a possibilidade de mudanças reais é sempre interrompida por um "porém" (NBC, 02/08/200533, 06/10/200834; Johnston, CBS, 16/02/2004; Omar, CBS, 17/08/10).

Apesar disso, a $\mathrm{ABC}$ reportou que há uma grande participação das mulheres no âmbito político, com indivíduos manifestando-se a favor dos direitos das mulheres no seu país - ativistas engajadas na Assembleia do país ou fazendo parte de partidos (ABC, 06/01/2006 $\mathrm{ABC}, 07 / 01 / 2006^{36}$ ) -, é apontado que muitas delas apresentaram visões diferentes de como a constituição do país deveria ser estabelecida - em que algumas procuram garantir

\footnotetext{
28 "The problem is more acute for women who have come under attack simply for wearing makeup or refusing to don head scarves and head-to-toe black robes" (NBC, 06/10/2008)

${ }^{29}$ Vide nota de rodapé número 13 (NBC, 2008).

30 "The Iraqi woman has endured torture, murder, confinement, execution, and banishment, just like other[s] in Iraqi society at the hands of Saddam Hussein's criminal gang." (McElroy, FOX News, 11/02/2003)

31 "Ibtisam, 40, was injured by an iron bar as she fled shelling in the U.S.-led invasion and was forced to have her uterus surgically removed. During the sectarian carnage that followed, a Shi'ite militia kidnapped her husband and killed him." (al-Salhy; Colesk, NBC, 12/11/2013)

${ }^{32}$ Vide nota de rodapé número 15 (CNN, 2007).

${ }^{33}$ Vide nota de rodapé número 20 (NBC, 2008).

${ }^{34}$ Vide nota de rodapé número 12 (NBC, 2008).

${ }^{35}$ Vide nota de rodapé número 18 (ABC, 2006).

${ }^{36}$ SOME Fear Loss of Women's Rights in Iraq. $A B C$, Nova Iorque, 07 jan. 2006. Disponível em: <https:// abcnews.go.com/WNT/IraqCoverage/story?id=666790>. Acesso em: 19/04/2020.
} 
os direitos já conquistados, outras manifestam preferência pelo embasamento nas tradições das leis islâmicas (ABC, 07/01/2006) ${ }^{37}$.

Com base nessas reportagens, podemos perceber que a emissora dá mais ênfase para os conflitos existentes entre as mulheres iraquianas, em detrimento da exploração de sua participação política. De qualquer forma, uma das grandes conquistas das mulheres foi a garantia de participação feminina no governo do Iraque, tendo $25 \%$ dos assentos na Assembleia Nacional de Transição assegurados para elas, um mecanismo que aumentou de forma substancial a representatividade das mulheres no governo e começou a ser visto como uma ferramenta de acesso ao poder pelas civis (Monshipouri, 2004: 191; CBS, 03/03/201038; Evans, CNN, 09/03/10).

Contudo, seja a participação das mulheres na política oficial, como agentes de segurança ou como extremistas, parece haver empecilhos intransponíveis para sua participação política - o governo conservador, a falta de um governo com confiança do povo, e/ou seu medo de sofrer retaliações de extremistas (NBC, 06/10/2008) ${ }^{39}$. Por isso, muitas vezes é dito que as mulheres buscam os EUA para ajudá-las (NBC, 02/08/2005) ${ }^{40}$. Por fim, uma matéria da CNN de 2013, refletindo nos 10 anos de intervenção dos EUA no país, traz um olhar mais pessimista em relação a situação geral das mulheres no Iraque, apontando os desafios de participação, de direitos, de violência e econômicos que as mulheres iraquianas ainda enfrentam (Salbi, 18/03/13).

Para grupos defensores dos direitos das mulheres, o aumento da violência contra as mulheres se deve a um conjunto de fatores, a pressão social e econômica, a falta de vontade pública e política de reverter essa conjuntura, e o aumento do conservadorismo religioso que muitas vezes justifica a violência. Isso tudo faz com que a memória do que as mulheres iraquianas já foram e já tiveram seja esquecida, segundo Zainab Salbi (CNN, 2013). Como um todo, dez anos após a invasão, há uma imagem e uma expectativa de que as mulheres estão mais participativas, mais inseridas na sociedade e que a igualdade para elas tem aumentado pós-guerra. Mas na realidade, mesmo que as mulheres tenham obtido alguns benefícios, elas perderam bem mais do que ganharam desde 2003 (Zainab Salbi, CNN, 2013).

Tendo em vista o estudo extenso de Neshat (2003) e Al-Ali (2012) sobre os movimentos de mulheres do Iraque e seu grande envolvimento histórico no país, podemos perceber que as notícias analisadas se mantêm dentro de um discurso simplista, raramente reconhecendo a extensa trajetória das mulheres de luta por direitos. Apenas uma das notícias (al-Salhy; Colesk, NBC, 2013; Thomas Reuters Foundation, 2013) aponta a vanguarda iraquiana no Oriente Médio quanto aos direitos das mulheres.

Somente nos anos mais recentes é que se implementa um pouco mais de criticidade em relação às ações neocolonialistas dos Estados Unidos no período de 2003 a 2013, porém,

\footnotetext{
${ }^{37}$ Vide nota de rodapé número 36 (ABC, 2006).

${ }^{38}$ Vide nota de rodapé número 21 (CBS, 2010).

${ }^{39}$ Vide nota de rodapé número 13 (NBC, 2008).

${ }^{40}$ Vide nota de rodapé número 20 (NBC, 2008).
} 
essa é voltada para assuntos envolvendo normas, leis e os Direitos Humanos em geral, e não para a questão das mulheres. Uma conquista notável nesse cenário pós-invasão foi a mobilização política das mulheres para conquistarem uma cota de $25 \%$ na Assembleia do país, assegurando sua representação política (Al-Ali, 2012: 114- 118). Porém, ao trazerem esses dados, as emissoras CBS $(03 / 03 / 2010)^{41}$ e NBC $(02 / 08 / 2005)^{42}$ o fazem como se estivesse necessariamente atrelado à excelência dos Estados Unidos em promover os direitos das mulheres transnacionalmente.

Portanto, uma perspectiva atrelada ao Feminismo Transnacional, que refletisse sobre a complexidade e a pluralidade de mulheres no Iraque, bem como acerca de seus movimentos, não se fez presente, demarcando que o orientalismo de gênero ainda é forte. Assim, a existência de diferenças (materiais ou discursivas) em movimentos, culturas e sociedades é obscurecida em favor de um único espectro, de um pós-feminismo imperialista e neoliberal, o qual continuamente possibilita intervenções externas, como o foi a Guerra do Iraque de 2003 (Dosekun, 2015; Abu-Lughod, 2013).

Além disso, podemos observar nas notícias o que Banwell (2015), Al-Ali (2012) e Neshat (2003) apontam: o cenário já problemático do Iraque foi exacerbado após a intervenção de 2003, com aumento da violência contra as mulheres - apesar do discurso de salvaguarda das mulheres iraquianas pelo governo estadunidense. Ainda, o teor das notícias analisadas foca principalmente naquilo que Zine (2006), Abu-Lughod (2013) e Yeğenoğlu (1998) explicitam do estereótipo da mulher árabe: suas vestimentas - como um dos principais problemas a serem enfrentados -, sua religião, e a opressão sofrida pelos homens ao seu redor.

Apesar de notarmos uma conotação orientalista nas notícias, a qual afeta na percepção que se constrói sobre essas mulheres, essas notícias não focaram na questão da mobilização das mulheres iraquianas. Dessa forma, o discurso orientalista, analisado através das notícias, afeta na interpretação dos movimentos das mulheres iraquianas no sentido de não trazer em perspectiva o quanto elas são atuantes na sociedade e as organizações das quais elas fazem parte. Suas conquistas são apontadas com maiores méritos para os EUA, mantendo o discurso orientalista de salvação das mulheres iraquianas.

\section{CONSIDERAÇÕES FINAIS}

A história do Iraque demonstra a constante presença dos movimentos das mulheres. Desde aqueles construídos por elas mesmas, até os impostos pelo governo, as mulheres sempre foram presentes na construção e manutenção do Estado iraquiano (Neshat, 2003). As guerras do Golfo de 1991 e, principalmente, a Guerra ao Terror de 2003, impactaram na vida dessas mulheres, levando à perda de direitos e ao retorno ao conservadorismo (Al-Ali, 2012; Human Rights Watch, 2003). 0 discurso estadunidense que justificou a intervenção

\footnotetext{
${ }^{41}$ Vide nota de rodapé número 21 (CBS, 2010).

${ }^{42}$ Vide nota de rodapé número 20 (NBC, 2008).
} 
de 2003, no entanto, afirmava que as mulheres iraquianas necessitavam de sua ajuda e dos direitos que apenas o Ocidente poderia levar até elas (Abu-Lughod, 2013).

No período de 2003 a 2013 e analisando notícias de cinco emissoras, encontramos apenas 20 notícias sobre a temática de mulheres do Iraque e movimento das mulheres no país para ser analisadas. Nessa análise, elas são representadas como mulheres oprimidas pelo véu, pela religião, pelos homens de sua sociedade e que, mesmo quando possuem uma chance de articulação, tem dificuldades intransponíveis - necessitando a ajuda do estadunidense para a conquista de seus direitos. As notícias apontam que mulheres iraquianas são aquelas a quem se deve ajudar; o discurso apresenta mulheres unidimensionais, obscurecendo a existência de diferentes formas de feminismo e luta - ou, como diz Abu-Lughod (2013), a escolha de diferentes futuros. Além disso, foi percebido que os movimentos das mulheres iraquianas e suas organizações sociais e políticas raramente são retratadas. Portanto, ao efetuar a análise dessa amostra, não se pode chegar a pontos conclusivos acerca de como esse discurso vem impactando na interpretação dos movimentos das mulheres do Iraque, uma vez que ele não é enfatizado.

Contudo, foi possível perceber que houve uma mudança lenta e gradativa no teor das notícias, passando a ser mais crítico quanto ao papel dos EUA e a invasão de 2003. No entanto, para verificar se essa mudança foi momentânea ou é contínua, seria necessário aumentar o escopo de emissoras e o período de análise, uma vez que ainda existe uma lacuna no estudo das mulheres iraquianas e seus movimentos sociais e políticos. Principalmente analisando o período pós-invasão de 2003, e estudos que surjam do Ocidente para refletir com criticidade acerca do assunto, reconhecendo que existem diversas possibilidades de existências que diferem daquela única legitimada pelo Ocidente.

\section{REFERÊNCIAS}

ABU-LUGHOD, Lila. Do Muslim Women Need Saving? Massachusetts: Harvard University Press, 2013.

Orientalism and Middle East Feminist Studies, 2001.

AL-ALI, Nadje. The Iraqi Women's Movement: Past and Contemporary Perspectives'. Mapping Arab Women's Movements: A Century of Transformations from Within. p. 105-121, 2012. AL-ALI, Nadje. PRATT, Nicola. Women and War in the Middle East: transnational perspectives, 2009.

ANDERSON, Lisa. The State in the Middle East and North Africa. Comparative Politics, v. 20, n. 1, p. 1-18, 1987. Disponível em: <http://www.jstor.org/stable/421917>. Acesso em: 14 abril 2018. 
BANWELL, Stacy. Globalisation masculinities, empire building and forced prostitution: a critical analysis of the gendered impact of the neoliberal economic agenda in post-invasion/ occupation Iraq. Third World Quarterly, v. 36, n. 4, p. 705-722, 2015.

CAMPT, Tina. what's the 'trans' and where's the 'national' in transnational feminist practice? - a response". Feminist Review. p. e130-e135, 2011.

CHAISE, Mariana Falcão. Feminismo Transnacional: uma lente para o Anti-Orientalismo. Revista Estudos Feministas, v. 24, n. 3, p. 1027-1030, 2016.

CHEW, Huibin Amelia. What's left? After 'imperial feminist' hijackings. In: MOHANTY, Chandra Talpade; RILEY, Robin L.; PRATT, Minnie Bruce. Feminism and War: Confronting US Imperialism, p. 84-99, p 179-194, 2008.

DOSEKUN, Simidele. For western girls only? Post-feminism as transnational culture. Feminist Media Studies, v. 15, n. 6, p. 960-975, 2015.

FERABOLLI, Sílvia. Relações Internacionais Do Mundo Árabe: Os Desafios Para a Realização Da Utopia Pan-Arabista. Curitiba: Juruá. 2009.

GOMES, Mariana S. O imaginário social <Mulher Brasileira > em Portugal: uma análise da construção de saberes, das relações de poder e dos modos de subjetivação. 2013. 346 f. Tese (Doutorado em Sociologia) - Instituto Universitário de Lisboa, Lisboa.

HO, Christina. Responding To Orientalist Feminism: Women's Rights and the War on Terror. Australian Feminist Studies, v. 25, n. 66, p. 433-439, 2010.

HALLIDAY, Fred. The Middle East in International Relations: Power, Politics and Ideology. Cambridge: Cambridge University Press. 2005.

HARMON, Mark; MUENCHEN, Robert. Semantic framing in the build-up to the Iraq war: Fox v. CNN and other US broadcast news programs. ETC: A Review of General Semantics, p. 12-26, 2009.

HUMAN RIGHTS WATCH. Background on Women's Status in Iraq Prior to the Fall of the Saddam Hussein Government. 2003. Disponível em: <https://www.hrw.org/legacy /backgrounder/ wrd/iraq-women.htm>. Acesso em: 02 jul. de 2018.

KHALID, Maryam. Gender, Orientalism and Representations of the 'Other' in the War on Terror. Global Change, Peace \& Security. v. 23, n. 1, p. 15-29, 2011.

MCLAREN, Margaret A. Decolonizing feminism: transnational feminism and globalization. 2017.

MOHANTY, Chandra Talpade. 'Under Western Eyes' Revisited: Feminist Solidarity through Anticapitalist Struggles. Signs: Journal of Women in Culture and Society, v. 28, n. 2, p. 499-535, jan. 2002.

MOHANTY, Chandra Talpade; RILEY, Robin L.; PRATT, Minnie Bruce. Feminism and War: Confronting US Imperialism, p. 84-99, p 179-194, 2008. 
MONSHIPOURI, Mahmood. 'O mundo muçulmano em uma era global: a proteção dos direitos das mulheres.' Contexto Internacional 26, no. 1, p. 187-217, 2004.

NESHAT, Saeid N. A Look into the Women's Movement in Iraq. Farzaneh, v. 6, n. 11, p. 54-65, 2003.

NUSAIR, Isis. Gendered, racialized, and sexualized torture at Abu Ghraib. In: MOHANTY, Chandra Talpade; RILEY, Robin L.; PRATT, Minnie Bruce. Feminism and War: Confronting US Imperialism, p. 84-99, p 179-194, 2008.

OZA, Rupal. The entanglements of transnational feminism and area studies. Environment and Planning D: Society and Space, v. 34, n. 5, p. 836-842, 2016.

PEW RESEARCH CENTER. Democrats report much higher levels of trust in a number of news sources than Republicans. Disponível em: <https://www.journalism.org/2020/ 01/24/ democrats-report-much-higher-levels-of-trust-in-a-number-of-news-sources-than-republicans/>. Acesso: 16/042020.

SAID, E. W. Orientalismo: o Oriente como invenção do Ocidente. Editora Companhia das Letras, 1996.

THOMAS REUTERS FOUNDATION. Poll: Women's Rights In The Arab World Full Results. Disponível em: <https://news.trust.org/application/velocity/spotlight-extensions /womensrights-in-the-arab-world/english/documents/final-results.pdf>. Acesso em: 23/04/2020. YEĞENOĞLU, Meyda. Colonial fantasies: Towards a feminist reading of Orientalism. Cambridge University Press, 1998.

ZINE, Jasmin. Between Orientalism and Fundamentalism: The Politics of Muslim Women's Feminist Engagement. Muslim World Journal of Human Rights, edição especial Post-September 11th Developments in Human Rights in the Muslim World, 2006.

\section{FONTES CONSULTADAS}

AL-SALHY, Suadad; COLESK, Isabel. Iraqi women lament costs of U.S invasion. NBC, Nova Iorque, 12 nov. 2013. Disponível em: <https://www.nbcnews.com/news/ world/iraqiwomen-lament-costs-u-s-invasion-flna2D11582249>. Acesso em: 17 abr. 2020.

BABAROVIC, Tina. Iraqi Women Train as Police Officers. $A B C$, Nova Iorque, 07 jan. 2006. Disponível em: <https://abcnews.go.com/WNT/story?id=131447\&page=1>. Acesso em: 19 abr. 2020.

BRYSON, Donna. A Call To Protect Iraqi Women. CBS, Nova Iorque, 15 jul. 2003. Disponível em: <https://www.cbsnews.com/news/a-call-to-protect-iraqi-women/>. Acesso em: 16 abr. 2020. 
EVANS, Tom. Iraqi activist: Women's rights must be focus for new parliament. CNN, Atlanta, 09 mar. 2010. Disponível em: <https://edition.cnn.com/2010/WORLD/meast/03/ 08/iraq. womens.rights/index.html>. Acesso em: 15 abr. 2020.

GHADISHAH, Arash. Harsh Reality for Many Iraqi Women. $A B C$, Nova Iorque, 10 mai. 2007. Disponível em: <https://abcnews.go.com/amp/International/story?id=3161082\& page=1 >. Acesso em: 19 abr. 2020.

JOHNSTON, Lauren. Strong, Smart \& Female In Iraq. CBS, Nova Iorque, 16 fev. 2004. Disponível em: <https://www.cbsnews.com/news/strong-smart-female-in-iraq/>. Acesso em: 15 abr. 2020.

MCELROY, Wendy. Iraqi Women Brutalized by Saddam Published February. FOX, Los Angeles, 11 fev. 2003. Disponível em: <https://www.foxnews.com/story/iraqi-women- brutalized-by-saddam>. Acesso em: 15 abr. 2020.

MCMULLEN, Troy. Iraqi Women Targeted by Campaign of Violence. $A B C$, Nova Iorque, 12 fev. 2009. Disponível em: <https://abcnews.go.com/amp/International/story?id=3870202\&page $=1>$. Acesso em: 16 abr. 2020.

OMAR, Manal. Iraqi Women: Hearing From a Forgotten Voice. CBS, Nova Iorque, 17 ago. 2010. Disponível em: <https://www.cbsnews.com/news/iraqi-women-hearing-from-aforgotten-voice/>. Acesso em: 16 abr. 2020.

RASHID, Aadel. Iraqi Women Can Now Say No to Hijab or Head Scarf. $A B C$, Nova Iorque, 25 mar. 2009. Disponível em: <https://abcnews.go.com/International/story?id=7168860 \&page $=1>$. Acesso em: 19 abr. 2020.

SALBI, Zainab. Why women are less free 10 years after the invasion of Iraq. CNN, Atlanta, 13 mar. 2013. Disponível em: <https://edition.cnn.com/2013/03/18/opinion/iraq-warwomen-salbi/ index.html >. Acesso em: 15 abr. 2020. 
